\title{
Prognostic perspectives of PD-L1 combined with tumor-infiltrating lymphocytes, Epstein-Barr virus, and microsatellite instability in gastric carcinomas
}

Euno Choi ${ }^{1+}$, Mee Soo Chang ${ }^{1 *+} \mathbb{D}$, Sun-ju Byeon ${ }^{1}$, Heejin Jin ${ }^{2}$, Kyeong Cheon Jung ${ }^{3}$, Haeryoung Kim³ Kook Lae Lee ${ }^{4}$, Won Kim ${ }^{4}$, Jin Hyun Park ${ }^{4}$, Ki Hwan Kim ${ }^{4}$, Jin-Soo Kim ${ }^{4}$, In Sil Choi ${ }^{4}$, Dong-Seok Han ${ }^{5}$, Hye Seong $\mathrm{Ahn}^{5}$ and Seung Chul Heo ${ }^{5}$

\begin{abstract}
Background: The prognostic potential of PD-L1 is currently unclear in gastric carcinomas, although the immune checkpoint PD-1/PD-L1 inhibitors have produced promising results in clinical trials.

Methods: We explored the prognostic implications of programmed death ligand 1 (PD-L1) in 514 consecutive surgically-resected gastric carcinomas. Overall survival and recurrence-free survival were evaluated. Immunohistochemistry for PD-L1, CD8, FOXP3, and PD-1, and molecular grouping by in situ hybridization for Epstein-Barr virus (EBV-encoded small RNAs and multiplex PCR for microsatellite instability (MSI) markers were performed. Additionally, to explore the function inherent to PD-L1, PD-L1-specific siRNA transfection, cell proliferation, invasion, migration and apoptosis assays were conducted in five gastric carcinoma cell lines.

Results: PD-L1(+) tumor and immune cells were observed in 101 (20\%) and 244 patients (47\%), respectively. "Tumoral PD-L1(+)/immune cell PD-L1(-)/CD8 ${ }^{+/ l o w}$ tumor-infiltrating lymphocytes (TILS)," and more advanced-stage tumors were associated with unfavorable clinical outcomes in the entire cohort through multivariate analysis. Furthermore, tumoral PDL1(+)/FOXP3 $3^{+/ \text {low }}$ TILs were associated with worse clinical outcomes in EBV-positive and MSI-high carcinomas. Tumoral PD-L1(+) alone was an adverse prognostic factor in EBV-positive carcinomas, but not in MSI-high carcinomas, whereas PD-L1(+) immune cells or FOXP3 ${ }^{+/ \text {high }}$ TILs alone were correlated with a favorable prognosis. PD-L1 knockdown in gastric carcinoma cells suppressed cell proliferation, invasion and migration, and increased apoptosis, which were all statistically significant in two $\operatorname{EBV}(+)$ cell lines, but not all in three $\operatorname{EBV}(-)$ cell lines.

(Continued on next page)
\end{abstract}

\footnotetext{
* Correspondence: meesooch@snu.ac.kr

†Euno Choi and Mee Soo Chang contributed equally to this work.

'Department of Pathology, Seoul National University Boramae Hospital, Seoul

National University College of Medicine, 20 Boramae-ro 5-gil, Dongjak-gu,

Seoul 07061, Republic of Korea

Full list of author information is available at the end of the article
}

(c) The Author(s). 2020 Open Access This article is licensed under a Creative Commons Attribution 4.0 International License, which permits use, sharing, adaptation, distribution and reproduction in any medium or format, as long as you give appropriate credit to the original author(s) and the source, provide a link to the Creative Commons licence, and indicate if changes were made. The images or other third party material in this article are included in the article's Creative Commons licence, unless indicated otherwise in a credit line to the material. If material is not included in the article's Creative Commons licence and your intended use is not permitted by statutory regulation or exceeds the permitted use, you will need to obtain permission directly from the copyright holder. To view a copy of this licence, visit http://creativecommons.org/licenses/by/4.0/ The Creative Commons Public Domain Dedication waiver (http://creativecommons.org/publicdomain/zero/1.0/) applies to the data made available in this article, unless otherwise stated in a credit line to the data. 


\begin{abstract}
(Continued from previous page)
Conclusions: The prognostic impact of PD-L1 may depend on the tumor microenvironment, and statuses of EBV and MSI, although PD-L1 innately promotes cancer cell survival in cell-based assays. The combination of "tumoral PD-L1/ immune cell PD-L1/CD8 ${ }^{+}$TILs" may serve as an independent prognostic factor. Tumoral PD-L1(+)/immune cell PD-L1(-)/ $\mathrm{CD}^{+/ \text {low }}$ TILs showing a worse prognosis may be beneficial for combinatorial therapies of anti-PD-L1/PD-1 and anticytotoxic T-lymphocyte associated antigen 4 (CTLA4) that would promote effector T cells, thus attack the tumor.
\end{abstract}

Keywords: Stomach cancer, PD-L1, Tumor-infiltrating lymphocytes, Epstein-Barr virus, Microsatellite instability, Prognosis

\section{Background}

Gastric carcinoma is the third most common cancer, and the third or fourth most common cause of cancerrelated deaths worldwide [1]. Recently, targeting programmed cell death 1 (PD-1)/programmed cell death ligand 1 (PD-L1) immune checkpoint inhibitors have led to major progress in cancer immunotherapy; resulting in positive outcomes in clinical trials across various solid malignancies, including gastric carcinomas [2, 3]. Tumor cells aberrantly express PD-L1, and exploit PD-1/PD-L1 molecular brakes to evade immune surveillance $[4,5]$. Binding of the transmembrane PD-1 protein to its ligand, PD-L1, results in PD-1/T cell reoceptor inhibitory micro-clusters, which suppress the activation of $\mathrm{T}$ cells that could otherwise attack tumor cells [4].

The tumor microenvironment contains tumor cells that evade immunity by reprogramming immune cells, resulting in a dynamic immune environment [6]. Tumorinfiltrating lymphocytes (TILs), particularly, $\mathrm{CD}^{+}$cytotoxic $\mathrm{T}$ cells, support tumor cell killing functions $[7,8]$. However, their prolonged exposure to cancer cells may lead to the loss of their effector function [8]. Furthermore, PD-L1 promotes the initiation, maintenance, and expansion of forkhead box P3 $(\mathrm{FOXP} 3)^{+}$regulatory $\mathrm{T}$ cells (Treg), which inhibit antitumor $\mathrm{CD}^{+}$cytotoxic $\mathrm{T}$ cell functions [9]. Thus, immunomodulatory TILs may play an important role in the action of immune checkpoint blockades [10].

Many studies have investigated the prognostic potential of PD-L1 expression, but their data are controversial [11]; poor [12-15], good [16], and neutral [17] prognostic outcomes have all been reported. Given the convoluted immune interactions that occur in the tumor microenvironment, a combinatorial analysis of PD-L1, TILs, Epstein-Barr virus (EBV)-infection, and microsatellite instability (MSI) status is required. However, very few studies have employed such an integrative analysis.

In this study, we investigated PD-L1 expression in tumor and stromal immune cells, TILs $\left(\mathrm{CD}^{+}, \mathrm{FOXP3}^{+}\right.$, and $\mathrm{PD}-1^{+}$cells), and their concomitant prognostic value in a large cohort of gastric carcinomas and in molecular groups stratified by EBV-infection and MSI status. We aimed to define the prognostic implications of PD-L1 and immunomodulatory TILs, and further, provide guidance regarding the selection of patients for whom PD1/PD-L1 blockade immunotherapy could be advantageous.

\section{Methods \\ Patients}

We collected 514 surgically resected gastric carcinomas at the Seoul National University Boramae Hospital (Seoul, Korea) between 2006 and 2011. After surgical resection, patients in tumor stage II received adjuvant chemotherapy with 5 -fluorouracil (5-FU) or 5-FU/mitomycin-C, and patients in stage III or IVA, with 5-FU/cisplatin. None of patients were treated with neoadjuvant chemotherapy or immunotherapy. We reviewed medical records, patient outcomes, and histopathological findings, such as the World Health Organization (WHO) histologic classification, Lauren histologic type [18], and the tumor stage (pathological tumor-node-metastasis (pTNM)) based on the 7th American Joint Committee on Cancer [19]. Overall survival or recurrence-free survival was estimated from the date of surgery to death, tumor recurrence, or the last follow-up visit. The median follow-up period for overall survival was 77 months (mean: 63.8, range: $\sim 1-128$ ).

\section{Generating tissue microarray blocks}

After a histological review of all tumor sections, the portion of deepest tumor invasion was chosen from each donor block, and two tissue cores (diameter: $2 \mathrm{~mm} /$ core) per tumor were punched out using a trephine. The tissue cores were then inserted in a new recipient block containing fifty-nine tissue cores and one ink core as a direction marker. A total of eighteen tissue microarray blocks were thus prepared for immunohistochemistry.

\section{Immunohistochemistry for PD-L1, CD8, FOXP3, and PD-1}

Immunohistochemistry was performed using an automated immunostainer, the BenchMark Ultra IHC/ISH system (Ventana Medical Systems, Tucson, AZ, USA), according to the manufacturer's protocol. For PD-L1 immunohistochemistry, two different antibodies were utilized: clone E1L3N ${ }^{\circ}$ (1:30, Cell Signaling Technology, Danvers, MA, USA) was used for tumoral PD-L1 evaluation, and SP263 (Ready to use, Ventana Medical Systems) was used for stromal immune cell PD-L1 
detection; two different PD-L1 antibodies were used because they have been shown to have different efficiencies for the detection of tumoral PD-L1 and stromal immune cell PD-Ll [20]. We additionally conducted immunohistochemistry for CD8 (Ready to use; Novocastra, Leica Microsystems, Wetzlar, Germany), FOXP3 (236A/E7, 1: 30; Abcam, Cambridge, MA, USA), and PD-1 (NAT105, 1:30; Cell Marque, Rocklin, CA, USA).

PD-L1 expression in tumor cells was primarily scored based on staining intensity and percentage of stained tumor cells; any membranous staining was regarded as "positive expression" [21]. Stromal immune cell PD-L1 was categorized as positively expressed when membranous staining was present in $\geq 5 \%$ of the stromal immune cells at any staining intensity [22]. The number of CD8-, FOXP3-, or PD-1-positive cells were counted in ten contiguous high-power fields in heavily infiltrated areas; the absolute number of immunostained cells in each group was determined as an average per high-power field (400× magnification, $0.24 \mathrm{~mm}^{2}$ ) (Olympus BX51 microscope; Olympus, Tokyo, Japan). Finally, groups were classified into "low" and "high" populations based on the median number of $\mathrm{CD}^{+}, \mathrm{FOXP3}^{+}$, and $\mathrm{PD}-1^{+}$TILs cells, and then denoted as ${ }^{+/ l o w}$ or $^{\text {thigh }}$ [23].

\section{In situ hybridization for EBV-encoded small RNAs}

In situ hybridization for EBV-encoded small RNAs (EBER) was conducted using the BenchMark Ultra IHC/ ISH system and the INFORM EBER probe (Ventana Medical Systems) according to the manufacturer's instructions. EBV-infected cells were observed as blackcolored signals at the hybridization site using light microscopy. Only signals within tumor cell nuclei were considered EBV-positive carcinomas; black signals were seen in almost all cancer cell nuclei in EBV-positive cases.

\section{Microsatellite instability analysis}

Immunohistochemical staining for human mutL homo$\log 1$ (hMLH1; Ready to use; Ventana Medical Systems) and human mutS homolog 2 (hMSH2; Ready to use; Cell Marque) was initially performed on full-section paraffin blocks to screen for MSI-high cases, as reported previously [24]. Next, in cases showing loss patterns for either hMLH1 or hMSH2 nuclear expression, we extracted the DNA from paired normal and tumor tissues, and subsequently carried out MSI analysis using fluorescent multiplex PCR with five markers (BAT-25, BAT-26, D5S346, D17S250, and D2S123), as recommended by the National Cancer Institute (NCI) [25]. The PCR products were analyzed with a DNA autosequencer (ABI 3731 Genetic Analyzer; Applied Biosystems, Foster City, CA, USA). When a case was positive for two or more microsatellite markers, it was defined as MSI-high, in accordance with NCI criteria [25].

PD-L1 innate function study in gastric carcinoma cell lines We purchased SNU601, SNU216, and SNU719 from the Korean Cell Line Bank (Seoul, Korea), and AGS, from the American Type Culture Collection (Manassas, VA, USA). YCCEL1 was supplied by Dr. SY Rha [26, 27]. Cells were maintained at $37^{\circ} \mathrm{C}$ in RPMI 1640 (Gibco BRL, Rockville, MD, USA) supplemented with $10 \%$ fetal bovine serum, $2 \mathrm{mmol} / \mathrm{L}$ L-glutamine, and antibiotics (100 units/mL penicillin and streptomycin) in a humidified $5 \% \mathrm{CO}_{2} / 95 \%$ air atmosphere.

PD-L1-specific siRNA (s26547; 5'-GGCAUUUGCU GAACGCAUU-3') was acquired from Ambion Applied Biosystems (Austin, TX, USA), and a scrambled siRNA (sc-37,007) as the negative control, from Santa Cruz Biotechnology (Santa Cruz, CA, USA). We transfected cells $\left(25 \times 10^{4}\right.$ in a $60 \mathrm{~mm}$ plate $)$ with $200 \mathrm{pmol}$ siRNA using Lipofectamine 2000 (Invitrogen) per manufacturer's instructions. After $24 \mathrm{~h}$, western blot was performed; protein separated by SDS-PAGE gel was transferred onto PVDF membranes (Millipore, Bedford, MA, USA). Each membrane was treated with the primary antibody, PDL1 (17952-1-AP, 1:1000, Proteintech Fisher Scientific: Hampton, NH, USA), and then secondary antibodies (Cell Signaling). As a loading and transfer control, we used an antibody against $\beta$-actin (AC-15, 1:10000, Abcam).

To examine cellular proliferation, cells were seeded into 96 -well plates $\left(10^{3}\right.$ cells/well $)$ overnight, and incubated with $100 \mu \mathrm{L} /$ well of Cell Counting Kit-8 (CCK-8; Dojindo Laboratories, Kumamoto, Japan) for $2 \mathrm{~h}$ in the dark. Absorbance at $450 \mathrm{~nm}$ was measured using a spectrophotometer (Spectramax 190; Molecular Devices, Sunnyvale, CA, USA).

As for cell invasion, 24-well BioCoat Matrigel invasion chambers (BD Biosciences, San Diego, CA, USA) was used. Cells $\left(5 \times 10^{4} /\right.$ well in a 24-well plate) were placed in the upper chamber filled with $500 \mu \mathrm{L}$ serum-free media, and the lower chamber was filled with $700 \mu \mathrm{L}$ media supplemented with $10 \%$ fetal bovine serum; the chambers were then incubated for $18 \mathrm{~h}$ at $37^{\circ} \mathrm{C}$. Then, cells that invaded the lower chamber were stained with $4 \mu \mathrm{g} / \mathrm{mL}$ Calcein AM (BD Biosciences) in Hank's buffered saline at $37^{\circ} \mathrm{C}$ for $1 \mathrm{~h}$, and counted on a fluorescence microscope (Olympus IX71, Tokyo, Japan).

Apoptosis was calibrated with the Annexin V-FITC apoptosis kit (BD Biosciences). Cells $\left(10 \times 10^{4} /\right.$ well in a 6-well plate) were cultured in serum-free media, trypsinized (Invitrogen, Carlsbad, CA, USA), centrifuged, and re-suspended in Annexin V-binding buffer $(150 \mathrm{mmol} / \mathrm{L}$ $\mathrm{NaCl}, 18 \mathrm{mmol} / \mathrm{L} \mathrm{CaCl}_{2}, 10 \mathrm{nmol} / \mathrm{L}$ HEPES, $5 \mathrm{mmol} / \mathrm{L}$ $\mathrm{KCl}$, and $1 \mathrm{mmol} / \mathrm{L} \mathrm{MgCl}_{2}$ ). Cells were incubated with 
Table 1 Relationship Between Clinicopathological Features and PD-L1 Expression and Tumor-Infiltrating Lymphocytes in the Entire Cohort

\begin{tabular}{|c|c|c|c|c|c|c|c|}
\hline & \multirow[t]{2}{*}{ Total $(N=514)$} & \multicolumn{3}{|c|}{ PD-L1 in tumor cells } & \multicolumn{3}{|c|}{ PD-L1 in immune cells } \\
\hline & & \multicolumn{2}{|l|}{ positive } & negative & positive & \multicolumn{2}{|l|}{ negative } \\
\hline \multicolumn{8}{|l|}{ Sex } \\
\hline Male & $347(68 \%)$ & \multicolumn{2}{|l|}{$65(19 \%)$} & $282(81 \%)$ & 170 (49\%) & \multicolumn{2}{|l|}{$177(51 \%)$} \\
\hline Female & $167(32 \%)$ & \multicolumn{2}{|l|}{$36(22 \%)$} & $131(78 \%)$ & $74(44 \%)$ & \multicolumn{2}{|l|}{$93(56 \%)$} \\
\hline Age, median (years, range) & $65(27-88)$ & \multicolumn{2}{|l|}{$66(27-88)$} & $64(29-88)$ & $66(27-88)$ & \multicolumn{2}{|l|}{$64(30-86)$} \\
\hline \multicolumn{8}{|l|}{ Tumor site } \\
\hline Lower $1 / 3$ & $332(65 \%)$ & \multicolumn{2}{|l|}{$63(19 \%)$} & $269(81 \%)$ & $156(47 \%)$ & \multicolumn{2}{|l|}{$176(53 \%)$} \\
\hline Middle 1/3 & $103(20 \%)$ & \multicolumn{2}{|l|}{$17(17 \%)$} & $86(83 \%)$ & $50(49 \%)$ & \multicolumn{2}{|l|}{$53(51 \%)$} \\
\hline Upper $1 / 3$ & $79(15 \%)$ & \multicolumn{2}{|l|}{$21(27 \%)$} & $58(73 \%)$ & $38(48 \%)$ & \multicolumn{2}{|l|}{$41(52 \%)$} \\
\hline Histologic type & & \multicolumn{2}{|l|}{${ }^{*} P=0.008$} & & ${ }^{*} P<0.001$ & & \\
\hline Tubular adenocarcinoma & $415(81 \%)$ & \multicolumn{2}{|l|}{$87(21 \%)$} & $328(79 \%)$ & $214(52 \%)$ & \multicolumn{2}{|l|}{$201(48 \%)$} \\
\hline Poorly cohesive carcinoma & $83(16 \%)$ & $10(12 \%)$ & & $73(88 \%)$ & $22(27 \%)$ & \multicolumn{2}{|l|}{$61(73 \%)$} \\
\hline Mucinous carcinoma & $9(2 \%)$ & 0 & & $9(100 \%)$ & $2(22 \%)$ & $7(78 \%)$ & \\
\hline Undifferentiated carcinoma & $7(1 \%)$ & $4(57 \%)$ & & $3(43 \%)$ & $6(86 \%)$ & $1(14 \%)$ & \\
\hline Lauren classification & & ${ }^{*} P=0.023$ & & & ${ }^{*} P=0.019$ & & \\
\hline Intestinal & $286(56 \%)$ & $46(16 \%)$ & & $240(84 \%)$ & 149 (52\%) & $137(48 \%)$ & \\
\hline Diffuse & $228(44 \%)$ & $55(24 \%)$ & & $173(76 \%)$ & $95(42 \%)$ & $133(58 \%)$ & \\
\hline Lymphatic invasion & & ${ }^{*} P<0.001$ & & & & & \\
\hline Present & $230(45 \%)$ & $67(29 \%)$ & & $163(71 \%)$ & $100(43 \%)$ & $130(57 \%)$ & \\
\hline Depth of invasion (pT) & & ${ }^{*} P<0.001$ & & & $* P=0.006$ & & \\
\hline pT1 (mucosa, submucosa) & $262(51 \%)$ & $29(11 \%)$ & & $233(89 \%)$ & 137 (52\%) & $125(48 \%)$ & \\
\hline pT2 (muscularis proper) & $46(9 \%)$ & $10(22 \%)$ & & $36(78 \%)$ & $27(59 \%)$ & $19(41 \%)$ & \\
\hline pT3 (subserosa) & $97(19 \%)$ & $25(26 \%)$ & & $72(74 \%)$ & $42(43 \%)$ & $55(57 \%)$ & \\
\hline pT4 (serosa or beyond) & $109(21 \%)$ & $37(34 \%)$ & & $72(66 \%)$ & $38(35 \%)$ & $71(65 \%)$ & \\
\hline Lymph node metastasis & & ${ }^{*} P=0.008$ & & & ${ }^{*} P=0.004$ & & \\
\hline Present & $215(42 \%)$ & $54(25 \%)$ & & $161(75 \%)$ & $86(40 \%)$ & $129(60 \%)$ & \\
\hline Tumor stage (pTNM) & & ${ }^{*} P<0.001$ & & & $* P=0.008$ & & \\
\hline Stage I & 277 (54\%) & $36(13 \%)$ & & $241(87 \%)$ & $148(53 \%)$ & $129(47 \%)$ & \\
\hline Stage \| & $81(16 \%)$ & $23(28 \%)$ & & $58(72 \%)$ & $39(48 \%)$ & $42(52 \%)$ & \\
\hline Stage III & $130(25 \%)$ & $33(25 \%)$ & & $97(75 \%)$ & 49 (38\%) & $81(62 \%)$ & \\
\hline Stage IV & $26(5 \%)$ & $9(35 \%)$ & & $17(65 \%)$ & $8(31 \%)$ & $18(69 \%)$ & \\
\hline & Total $(N=514)$ & $\mathrm{CD}^{+}$popul & & $\mathrm{FOXP3}^{+} \mathrm{po}$ & ion & PD-1 $1^{+}$pop & \\
\hline & & high & low & high & low & high & low \\
\hline Sex & & & & & & & \\
\hline Male & $347(68 \%)$ & $177(51 \%)$ & $170(49 \%)$ & $161(46 \%)$ & $186(54 \%)$ & $126(36 \%)$ & $221(64 \%)$ \\
\hline Female & 167 (32\%) & $80(48 \%)$ & $87(52 \%)$ & 79 (47\%) & $88(53 \%)$ & $55(33 \%)$ & $112(67 \%)$ \\
\hline Age, median (years, range) & $65(27-88)$ & $65(27-88)$ & $65(30-86)$ & $66(27-84)$ & $63(29-88)$ & $67(40-88)$ & $63(27-88)$ \\
\hline Tumor site & & & & & & ${ }^{*} P=0.049$ & \\
\hline Lower $1 / 3$ & $332(65 \%)$ & $162(49 \%)$ & $170(51 \%)$ & $162(49 \%)$ & $170(51 \%)$ & 108 (33\%) & $224(67 \%)$ \\
\hline Middle 1/3 & $103(20 \%)$ & $46(45 \%)$ & $57(55 \%)$ & $46(45 \%)$ & $57(55 \%)$ & $37(36 \%)$ & $66(64 \%)$ \\
\hline Upper 1/3 & 79 (15\%) & $49(62 \%)$ & $30(38 \%)$ & $32(41 \%)$ & 47 (59\%) & $36(46 \%)$ & $43(54 \%)$ \\
\hline Histologic type & & & & $* P=0.001$ & & & \\
\hline Tubular adenocarcinoma & $415(81 \%)$ & $209(50 \%)$ & $206(50 \%)$ & $209(50 \%)$ & $206(50 \%)$ & $152(37 \%)$ & $263(63 \%)$ \\
\hline
\end{tabular}


Table 1 Relationship Between Clinicopathological Features and PD-L1 Expression and Tumor-Infiltrating Lymphocytes in the Entire Cohort (Continued)

\begin{tabular}{|c|c|c|c|c|c|c|c|}
\hline Poorly cohesive carcinoma & $83(16 \%)$ & $37(45 \%)$ & $46(55 \%)$ & $25(30 \%)$ & $58(70 \%)$ & $22(27 \%)$ & $61(73 \%)$ \\
\hline Mucinous carcinoma & $9(2 \%)$ & $4(44 \%)$ & $5(56 \%)$ & $3(33 \%)$ & $6(67 \%)$ & $1(11 \%)$ & $8(89 \%)$ \\
\hline Undifferentiated carcinoma & $7(1 \%)$ & $7(100 \%)$ & 0 & $3(43 \%)$ & $4(57 \%)$ & $6(86 \%)$ & $1(14 \%)$ \\
\hline Lauren classification & & ${ }^{*} P=0.004$ & & ${ }^{*} P=0.002$ & & & \\
\hline Intestinal & $286(56 \%)$ & $127(44 \%)$ & $159(56 \%)$ & $151(53 \%)$ & 135 (47\%) & 97 (34\%) & $189(66 \%)$ \\
\hline Diffuse & $228(44 \%)$ & $130(57 \%)$ & $98(43 \%)$ & 89 (39\%) & 139 (61\%) & $84(37 \%)$ & $144(63 \%)$ \\
\hline Lymphatic invasion & & ${ }^{*} P=0.033$ & & ${ }^{*} P=0.017$ & & ${ }^{*} P=0.041$ & \\
\hline Present & $230(45 \%)$ & $127(55 \%)$ & $103(45 \%)$ & $94(41 \%)$ & $136(59 \%)$ & $92(40 \%)$ & $138(60 \%)$ \\
\hline Depth of invasion (pT) & & ${ }^{*} P=0.006$ & & ${ }^{*} P<0.001$ & & & \\
\hline pT1 (mucosa, submucosa) & $262(51 \%)$ & $112(43 \%)$ & $150(57 \%)$ & $152(58 \%)$ & $110(42 \%)$ & $85(32 \%)$ & $177(68 \%)$ \\
\hline pT2 (muscularis proper) & $46(9 \%)$ & $31(67 \%)$ & $15(33 \%)$ & $22(48 \%)$ & $24(52 \%)$ & $20(43 \%)$ & $26(57 \%)$ \\
\hline pT3 (subserosa) & $97(19 \%)$ & $54(56 \%)$ & $43(44 \%)$ & $34(35 \%)$ & $63(65 \%)$ & $34(35 \%)$ & $63(65 \%)$ \\
\hline pT4 (serosa or beyond) & 109 (21\%) & $60(55 \%)$ & $49(45 \%)$ & $32(29 \%)$ & 77 (71\%) & $42(39 \%)$ & $67(61 \%)$ \\
\hline Lymph node metastasis & & & & ${ }^{*} P<0.001$ & & & \\
\hline Present & $215(42 \%)$ & $112(52 \%)$ & $103(48 \%)$ & 71 (33\%) & $144(67 \%)$ & 77 (36\%) & $138(64 \%)$ \\
\hline Tumor stage (pTNM) & & & & ${ }^{*} P<0.001$ & & & \\
\hline Stage I & 277 (54\%) & $126(45 \%)$ & $151(55 \%)$ & $163(59 \%)$ & $114(41 \%)$ & $95(34 \%)$ & $182(66 \%)$ \\
\hline Stage II & $81(16 \%)$ & $50(62 \%)$ & $31(38 \%)$ & $29(36 \%)$ & $52(64 \%)$ & $30(37 \%)$ & $51(63 \%)$ \\
\hline Stage III & $130(25 \%)$ & $66(51 \%)$ & $64(49 \%)$ & $39(30 \%)$ & 91 (70\%) & $44(34 \%)$ & $86(66 \%)$ \\
\hline Stage IV & $26(5 \%)$ & $15(58 \%)$ & $11(42 \%)$ & $9(35 \%)$ & $17(65 \%)$ & $12(46 \%)$ & $14(54 \%)$ \\
\hline
\end{tabular}

PD-L1 positive in tumor cells $(n=101)$; PD-L1 negative in tumor cells $(n=413)$; PD-L1 positive in immune cells $(n=244)$; PD-L1 negative in immune cells ( $n=270)$ $\mathrm{CD}^{+}$high $(n=257), \mathrm{CD}^{+}$low $(n=257) ; \mathrm{FOXP3}^{+}$high $(n=240) ; \mathrm{FOXP3}^{+}$low $(n=274), \mathrm{PD}^{-} 1^{+}$high $(n=181)$; PD $1^{+}$low $(n=333)$

$P$ values with statistically significant differences $(<0.05)$ are marked with an asterisk $(*)$

FITC-conjugated Annexin V $(1 \mu \mathrm{g} / \mathrm{mL})$ and propidium iodide $(50 \mu \mathrm{g} / \mathrm{mL})$ for $30 \mathrm{~min}$ at room temperature in the dark, and analyzed with FACScan flow cytometer (Becton Dickinson, Mountain View, CA, USA) and CellQuest software (Becton Dickinson).

Wound healing assay was performed to assess cell migration. A scratch was made in a 6-well plate of confluent cells $\left(25 \times 10^{4} /\right.$ well $)$ with the tip of a micropipette. Images were taken $24 \mathrm{~h}$ later on an inverted photomicroscope (Olympus IX71). Movements of individual cells were measured with NIH ImageJ software (http://rsb. info.nih.gov/ij/index.html).

\section{Statistical analysis}

Pearson's chi-squared test, two-tailed Student's t-test, Spearman's rank correlation coefficient, and MannWhitney U tests were used. Patient survival rates were calculated using the Kaplan-Meier method and log-rank test. We inputted parameters for which the $P$ value < 0.05 in univariate analysis into a Cox proportional hazard model (multivariate analysis) to calculate a hazard ratio (HR) and $95 \%$ confidence interval $(\mathrm{CI})$. A value of $P<0.05$ was considered statistically significant. All statistical analyses were conducted in SPSS Statistics version 21.0 for Windows (IBM SPSS Inc., Armonk, NY, USA) or the R Project for Statistical Computing 3.6.3 (https:// cran.r-project.org/bin/windows/base/).

\section{Results}

Clinicopathological features, PD-L1 expression, and TILs in the entire cohort

PD-L1(+) tumor cells were observed in 101 (20\%) out of 514 cases, and PD-L1(+) immune cells were observed in 244 cases (47\%) (Table 1 and Fig. 1). The dual expression of PD-L1 in both tumor and immune stromal cells was observed in 65 cases $(13 \%)$. The tumoral or immune cell PD-L1(+) subgroup manifested many more $\mathrm{CD} 8^{+}$, $\mathrm{FOXP}^{+}$, and PD- ${ }^{+}$TILs than the tumoral PD-L1(-) or immune cell PD-L1(-) subgroup $(P<0.05$, respectively) (Supplemental Table 1 and Supplemental Fig. 1).

Prognostic value of PD-L1 expression, TILs, EBV-infection, and MSI status in the entire cohort

The subgroup of more advanced-stage tumors (pTNM), Lauren diffuse type, presence of lymphatic invasion, tumoral PD-L1(+), immune cell PD-L1(-), or FOXP3 ${ }^{+/ \text {low }}$ TILs was associated with lower rates of overall survival via univariate analysis of the cohort $(N=514)$ (Fig. 2 and Supplemental Table 2). Since most patients with tumor recurrence did not survive, the above mentioned factors 


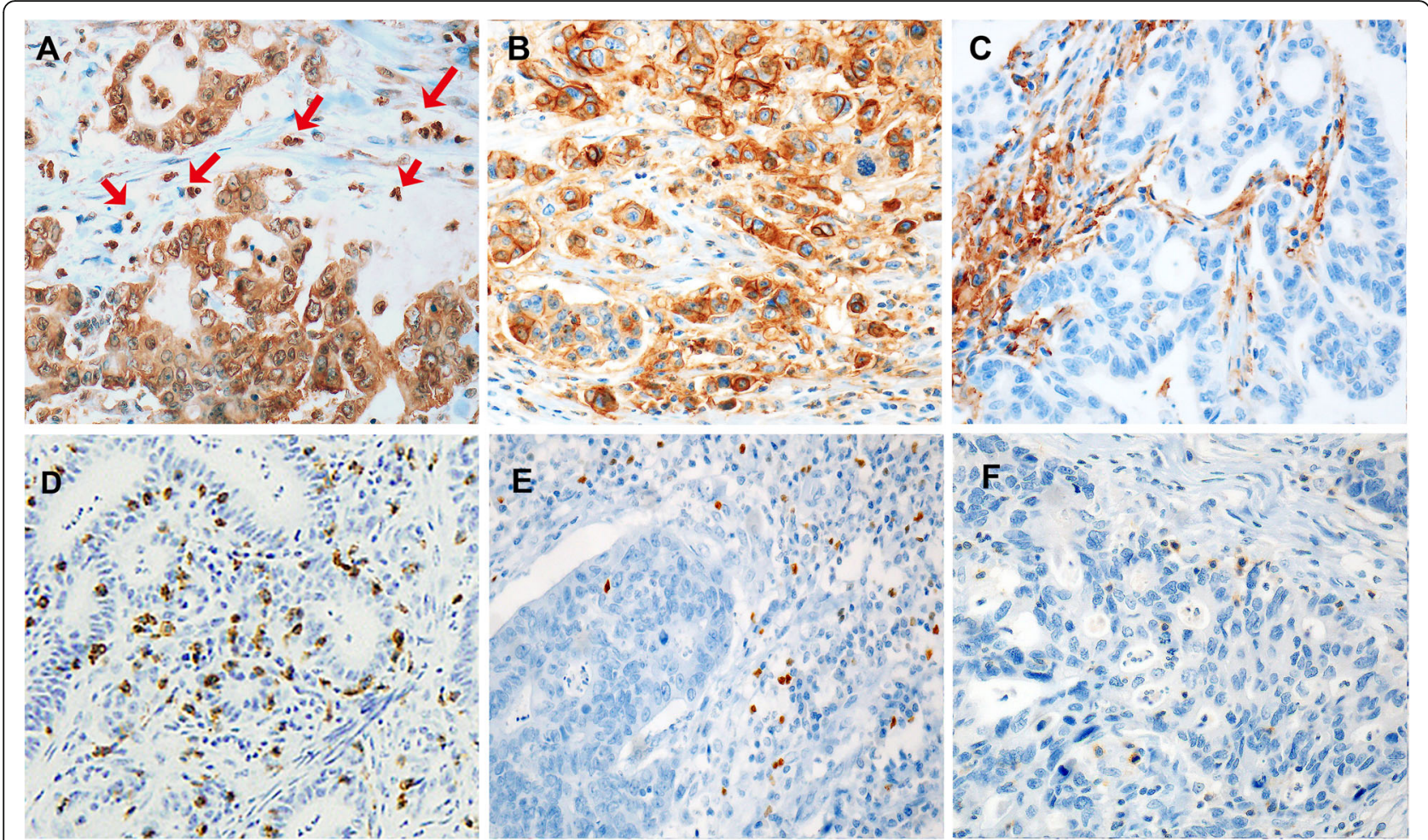

Fig. 1 Immunohistochemical features of PD-L1, CD8 ${ }^{+}, \mathrm{FOXP}^{+}$, and PD-1 ${ }^{+}$. (A-C) PD-L1 is expressed in three major patterns: a "Focal" PD-L1 expression in tumor cells and immune cells (red arrows). $\mathbf{b}$ "Diffuse (positive $\geq 10 \%$ of tumor cells)" PD-L1 expression in tumor cells and no staining in immune cells. c PD-L1 expression in immune cells only. (D-F) Note the high population in each line of tumor-infiltrating lymphocytes (TILS); d CD8 $8^{+/ h i g h}$ TILs, e FOXP3 ${ }^{+/ h i g h} \mathrm{TILS}$, and $\mathbf{f}$ PD-1 ${ }^{+/ \text {high }} \mathrm{TILS}$

were correlated with lower rates of recurrence-free survival (data not shown).

In our combined analysis of tumoral PD-L1 and each subtype of TILs, the combined subsets of tumoral PD$\mathrm{L} 1(+) / \mathrm{CD}^{+/ \text {low }}$ TILs, tumoral PD-L1(+)/immune cell PDL1(-), or tumoral PD-L1(+)/FOXP3/low TILs showed a worse clinical outcome based on univariate analysis $(P<0.05$, respectively). In combined analysis of three components from tumoral PD-L1, immune cell PD-L1, and each subtype of TILs, the combined subset of tumoral PD-L1(+)/immune cell PD-L1(-)/CD8 $8^{+ \text {low }}$ TILs was related with an adverse clinical outcome $(P<0.05)$.

Multivariate analysis showed that an unfavorable prognosis was maintained in more advanced-stage tumors, the subset of tumoral PD-L1(+)/CD8 ${ }^{+/ \text {low }}$ TILs, or the subset of tumoral PD-L1(+)/immune cell PD-L1(-)/CD8 ${ }^{+/ \text {low }}$ TILs, and all were independent prognostic factors $(P<0.05$, each) (Fig. 2 and Supplemental Table 2). EBV or MSI status alone were not a prognostic factor in the cohort.

Our analysis of only patients with "advanced gastric carcinoma" (AGC; cases with tumor invasion into the proper muscle or deeper; $N=253$ ) revealed that the prognostic factors for AGC were the same as those for the entire cohort, with two exceptions: AGC patients with a low population of $\mathrm{CD} 8^{+}$TILs showed lower rates of overall survival and recurrence-free survival through univariate analysis, and the MSI-high AGC group showed a more favorable clinical outcome $(P<0.05)$ (Supplemental Fig. 2).

\section{Clinicopathological features, PD-L1, and TILs in EBV- positive and MSI-high gastric carcinomas}

Of the 514 gastric carcinoma patients, there were 32 (6\%) and 53 (10\%) cases of EBV-positive and MSI-high gastric carcinomas, respectively; No patients were both EBV-positive and MSI-high. The remaining 429 cases of EBV-negative/non-MSI-high cases were classified as conventional gastric carcinomas (Fig. 3). Unlike the conventional group, EBV-positive carcinomas were located predominantly in the upper $1 / 3$ of the stomach and were more commonly Lauren diffuse type $(P<0.05$ for each). Additionally, MSI-high carcinomas showed more frequent lymphatic invasion, deeper invasion depth, and more advanced-stage tumors $(P<0.05)$ (Table 2$)$.

EBV-positive gastric carcinomas had higher incidences of tumoral PD-L1(+) and immune cell PD-L1(+), and larger numbers of $\mathrm{CD}^{+}, \mathrm{FOXP3}^{+}$, and PD- $1^{+}$TILs than conventional gastric carcinomas $(P<0.05$ for all comparisons $)$ (Table 3 and Supplemental Fig. 3). Specifically, tumoral PD-L1 and immune cell PD-L1 were expressed in 15 cases 


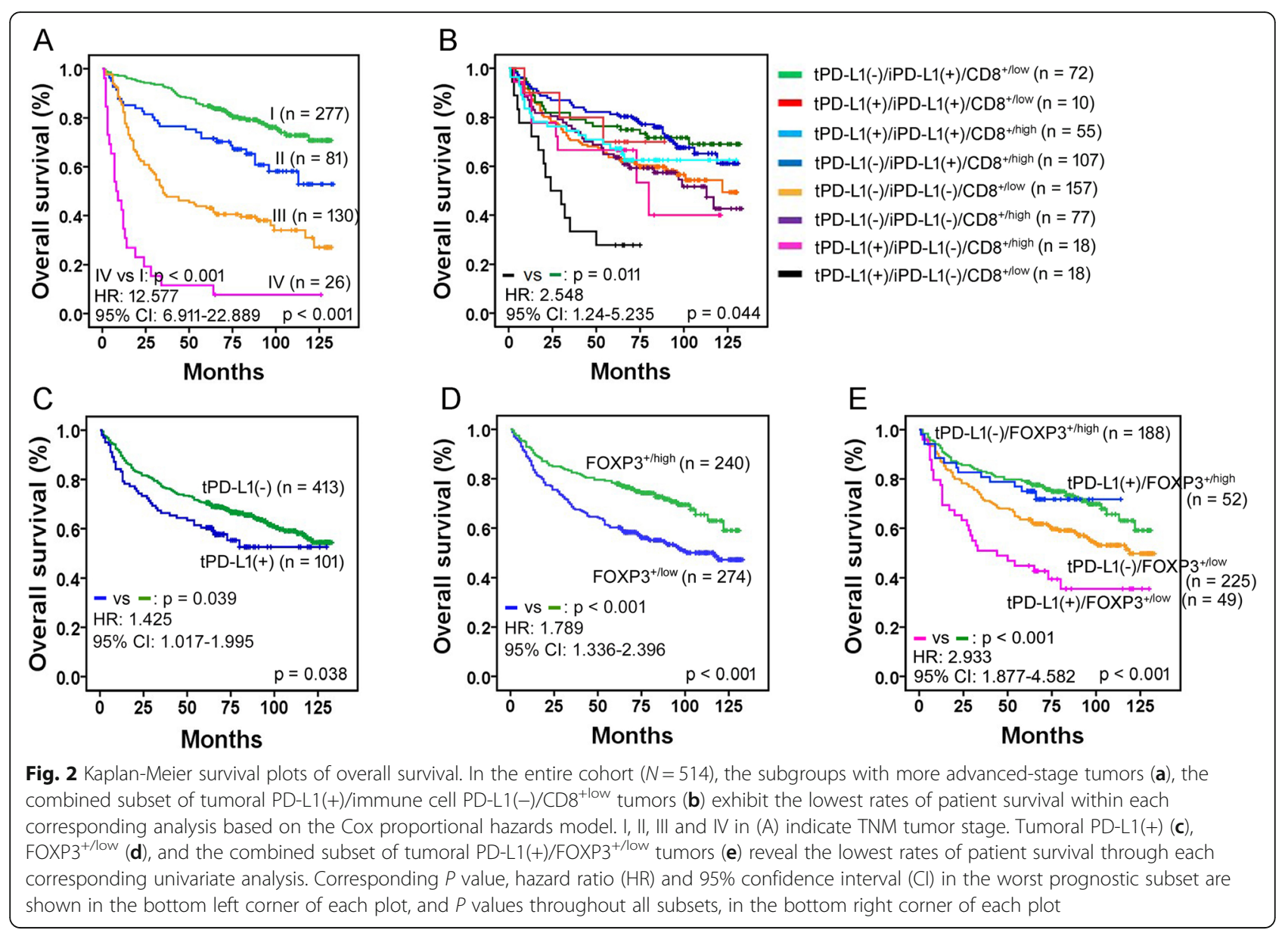

(47\%) and 30 cases (94\%), respectively, out of the 32 EBVpositive carcinomas. The $\mathrm{CD}^{+/ \text {high }}, \mathrm{FOXP}^{+/ \text {high }}$, and PD$1^{+/ \text {high }}$ TILs were found in 30 (94\% of EBV-positive subgroup), 21 (66\%), and 23 (72\%) cases, respectively. All 15 tumoral PD-L1(+)/EBV-positive carcinomas were enriched with $\mathrm{CD} 8^{+/ \text {high }}$ TILs.

MSI-high gastric carcinomas more commonly displayed tumoral PD-L1(+), immune cell PD-L1(+), or $\mathrm{CD}^{+/ \text {high }}$ TILs than conventional gastric carcinomas $(P<0.05$, each) (Table 3 and Supplemental Fig. 3). Specifically, tumoral PD-L1(+), immune cell PD-L1(+), and CD8 ${ }^{+/ \text {high }}$ TILs were observed in 27 (51\% of MSI-high carcinomas), 28 (53\%), and 38 cases (72\%), respectively.

\section{Prognostic value of PD-L1 and TILs in EBV-positive gastric carcinomas and MSI-high gastric carcinomas}

In EBV-positive gastric carcinomas, the tumoral PD-L1(+) subgroup showed lower rates of overall survival $(P<0.05)$ (Fig. 4 and Supplemental Table 3), and recurrence-free survival (data not shown). Through further univariate analysis of tumoral PD-L1 status combined with each line of TILs, tumoral PD-L1(+)/FOXP3 ${ }^{+/ l o w}$ TILs revealed a worse clinical outcome (Fig. 4 and Supplemental Table 4); however, tumor stage (pTNM) was the only independent prognostic factor in EBV-positive gastric carcinomas. The prognostic significance of tumoral PD-L1(+)/CD8 ${ }^{+/ \text {low }}$ TILs could not be statistically evaluated in the EBVpositive group because all tumoral PD-L1(+)/EBV-positive cases contained CD8 ${ }^{+/ \text {high }}$ TILs (Supplemental Fig. 4).

In MSI-high gastric carcinomas, the combined subset of tumoral PD-L1(+)/CD8 ${ }^{+/ \text {low }}$ TILs or tumoral PD-L1(+)/immune cell PD-L1(-)/CD8 ${ }^{+/ \text {low }}$ TILs was associated with an adverse outcome for patients $(P<0.05$, each) (Fig. 4$)$. None of other parameters showed a prognostic impact on overall survival or recurrence-free survival through univariate analysis. Accordingly, multivariate analysis could not be performed reliably. The covariate parameters of multivariate analysis must include significant factors from univariate analysis, and factors containing the same parameter (tumoral PD-L1 in this situation) should not be considered together when doing multivariate analysis.

Effects of PD-L1 knockdown in gastric carcinoma cells lines Cell proliferation, invasion and migration were lower in PD-L1-specific siRNA transfected cells than in scrambled siRNA-transfected control cells, whereas apoptosis 


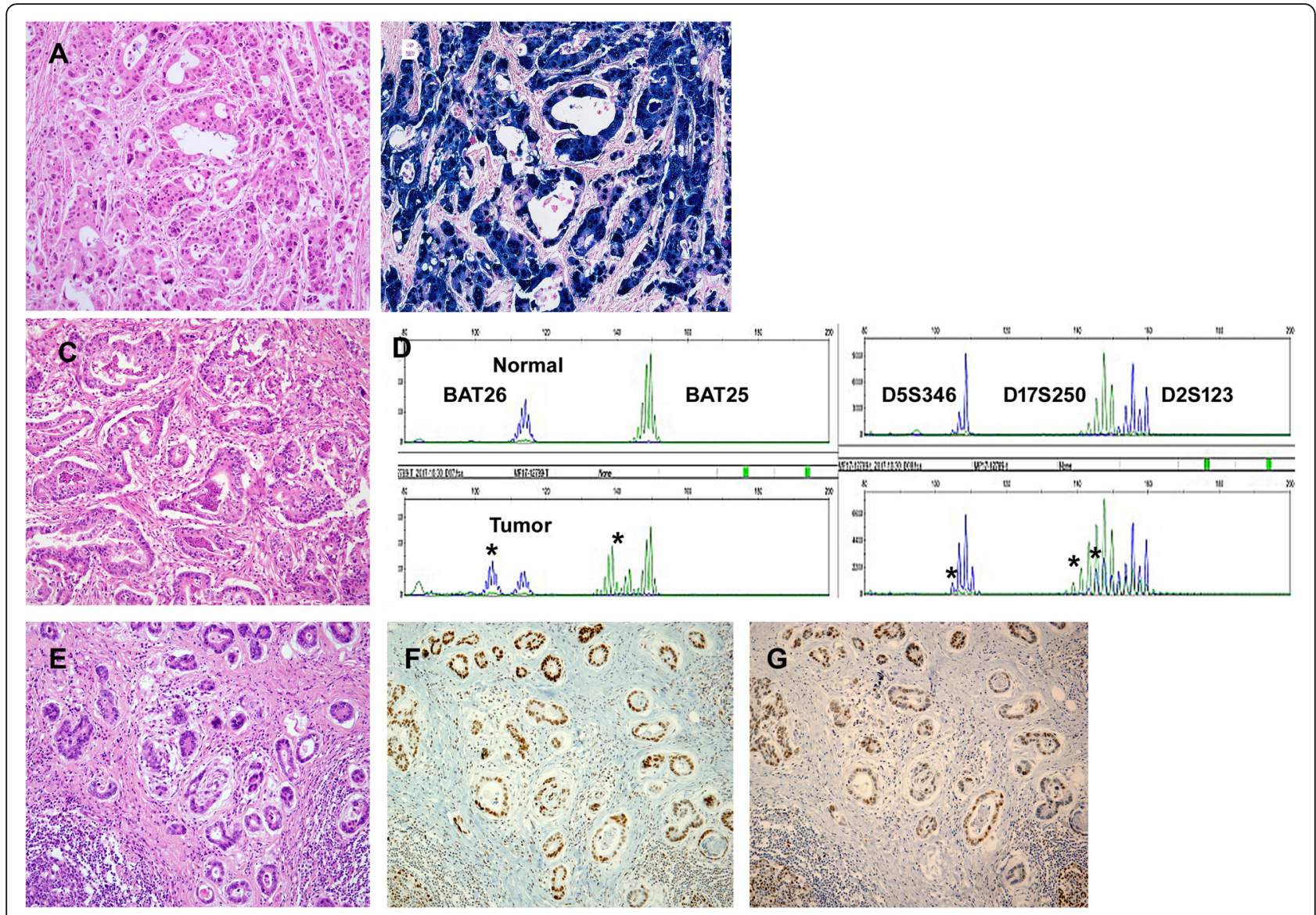

Fig. 3 Representative features of each molecular group. a, c, e Hematoxylin and eosin-stained images of each group. a-b Epstein-Barr virus (EBV)positive gastric carcinoma; b Black signals are detected in most tumor cell nuclei by in situ hybridization for EBV-encoded small RNAs. c-d Microsatellite instability (MSI)-high gastric carcinoma; d Microsatellites are recognized for five markers (BAT26, BAT25, D5S346, D17S250, and D2S123) by multiplex PCR, and are indicated with asterisks (*). e-g Conventional carcinoma (EBV-negative and non-MSI-high); hMLH1 f and hMSH2 $\mathbf{g}$ were retained in tumor cell nuclei

was higher. These findings were observed in all five gastric carcinoma cell lines; they were all statistically significant in two EBV-positive cell lines (Fig. 5), but not all in EBV-negative cell lines (Fig. 6). Specifically, SNU601 cells (EBV-negative) showed statistically significant differences with regard to proliferation, invasion, migration, and apoptosis, similar to the two EBV-positive cell lines. Our data imply that innate role of PD-L1 may be a facilitator of cancer cell survival.

\section{Discussion}

The present study indicates that the prognostic value of PD-L1 is complex, and contingent on the tumor microenvironment, and EBV and MSI statuses. There has been few study analyzing combined three components of "tumoral PD-L1, immune cell PD-L1 and TILs" in a single study all together. In this study, the combined subset of "tumoral PD-L1(+)/immune cell PD-L1(-)/CD8 $8^{+/ \text {low }}$ TILs" predicted a worse clinical outcome and were an independent prognostic factor; however, individual PD-
L1 or $\mathrm{CD}^{+}$TILs alone did not have an independent prognostic significance. In addition, $\mathrm{CD} 8^{+/ \text {low }}$ TILs was a worse prognostic factor in AGC group (Supplemental Fig. 2), specifically in tumor stage III (Supplemental Fig. 5) as assessed through univariate analysis. Unexpectedly, $\mathrm{CD}^{+/ \text {low }}$ TILs was correlated with well-known favorable prognostic factors such as Lauren intestinal type, less lymphatic invasion, and earlier tumor stage (Supplemental Table 5). In addition, tumoral PD-L1(+)/FOX$\mathrm{P}^{+/ \text {low }}$ TILs were associated with an unfavorable clinical outcome in the entire cohort, EBV-positive subgroup, and MSI-high subgroup through univariate analysis, while tumoral PD-L1(+)/immune cell PD-L1(-) status was associated with an unfavorable clinical outcome in the entire cohort only. Our combined analysis, which accounted for TILs in the tumor microenvironment, may provide reliable results regarding the prognostic value of PD-L1 expression. In this study, tumoral PD-L1 expression alone was an adverse prognostic factor, through univariate analysis, for all patients except those 
Table 2 Clinicopathological Features in Each Molecular Group

\begin{tabular}{|c|c|c|c|}
\hline & $\begin{array}{l}\text { Conventional } \\
(n=429)\end{array}$ & $\begin{array}{l}\text { EBV-positive } \\
(n=32)\end{array}$ & $\begin{array}{l}\text { MSI-high } \\
(n=53)\end{array}$ \\
\hline \multicolumn{4}{|l|}{ Sex } \\
\hline Male & $290(68 \%)$ & $24(75 \%)$ & $33(62 \%)$ \\
\hline Female & 139 (32\%) & $8(25 \%)$ & $20(38 \%)$ \\
\hline Age, median (years, range) & $65(27-88)$ & $63(45-88)$ & $64(34-82)$ \\
\hline Tumor site & & ${ }^{* a} P<0.001$ & \\
\hline Lower $1 / 3$ & $287(67 \%)$ & $4(13 \%)$ & 41 (77\%) \\
\hline Middle 1/3 & $85(20 \%)$ & $11(34 \%)$ & $7(13 \%)$ \\
\hline Upper $1 / 3$ & $57(13 \%)$ & 17 (53\%) & $5(9 \%)$ \\
\hline Histologic type & & & $*^{\mathrm{b}} P=0.006$ \\
\hline Tubular adenocarcinoma & $343(80 \%)$ & $29(91 \%)$ & $43(81 \%)$ \\
\hline Poorly cohesive & $76(18 \%)$ & $2(6 \%)$ & $5(9 \%)$ \\
\hline Mucinous carcinoma & $5(1 \%)$ & 0 & $4(8 \%)$ \\
\hline Undifferentiated & $5(1 \%)$ & $1(3 \%)$ & $1(2 \%)$ \\
\hline Lauren & & ${ }^{* a} P=0.029$ & \\
\hline Intestinal & $246(57 \%)$ & $12(38 \%)$ & $28(53 \%)$ \\
\hline Diffuse & $183(43 \%)$ & $20(63 \%)$ & $25(47 \%)$ \\
\hline Lymphatic invasion & & & ${ }^{* \mathrm{~b}} P<0.001$ \\
\hline Present & $182(42 \%)$ & 11 (34\%) & 37 (70\%) \\
\hline Depth of invasion (pT) & & & $*^{\mathrm{b}} p=0.031$ \\
\hline pT1 (mucosa, submucosa) & $229(53 \%)$ & 17 (53\%) & 16 (30\%) \\
\hline pT2 (muscularis proper) & $37(9 \%)$ & $3(9 \%)$ & $6(11 \%)$ \\
\hline pT3 (subserosa) & 79 (18\%) & $2(6 \%)$ & $16(30 \%)$ \\
\hline pT4 (serosa or beyond) & $84(20 \%)$ & $10(31 \%)$ & $15(28 \%)$ \\
\hline \multicolumn{4}{|l|}{ Lymph node metastasis } \\
\hline Present & 177 (41\%) & 10 (31\%) & $28(53 \%)$ \\
\hline Tumor stage (pTNM) & & & ${ }^{* b} P=0.028$ \\
\hline Stage I & $238(55 \%)$ & $20(63 \%)$ & 19 (36\%) \\
\hline Stage II & $64(15 \%)$ & $3(9 \%)$ & $14(26 \%)$ \\
\hline Stage III & 105 (24\%) & 7 (22\%) & 18 (34\%) \\
\hline Stage IV & $22(5 \%)$ & $2(6 \%)$ & $2(4 \%)$ \\
\hline
\end{tabular}

EBV Epstein-Barr virus, MSI Microsatellite instability; Conventional, EBV-negative and non-MSI-high

$P$ values with statistically significant differences $(<0.05)$ are marked with an asterisk $(*)$

${ }^{a} P$ value between EBV-positive gastric carcinomas and conventional gastric carcinomas

${ }^{\mathrm{b}} \mathrm{P}$ value between $\mathrm{MSI}-$ high gastric carcinomas and conventional gastric carcinomas

in the MSI-high gastric carcinoma subgroup. Our data on cell proliferation, invasion, migration and apoptosis using PD-L1 knockdown in gastric carcinoma cell lines demonstrated that the innate function of PD-L1 was to foster cancer cell survival, which is in line with prior studies $[28,29]$. The exact mechanisms by which PD-L1 exerts innately oncogenic effects remain to be better defined. The underlying processes may be related to be that PD-L1 expression is intrinsically regulated via various oncogenic pathways as well as extrinsically mediated via cytokines in tumor microenvironment [30]. As a fundamental immunology concept, tumoral PD-L1 expression helps the tumor to evade host immune surveillance, possibly contributing to more severe outcomes in cancer patients. However, the prognostic impact of tumoral PD-L1 expression in gastric carcinomas has been contradictory; poor [12-15], good [16], and neutral [17] prognostic outcomes have all been reported. The reasons for these discordant results largely lie in the use of different antibodies and cut-off values in the evaluation of PD-L1 expression [31]. Further, we addressed additional possibilities for the reasons, namely the analysis of individual factors only, the analysis of a small series, or potential selection bias (non-consecutive cases). The present study is important because it included a combined analysis of PD-L1, multiple lines of TILs, and EBV-infection and MSI status together in the same cohort of a large series composed of consecutive surgically-resected gastric carcinomas.

The present report advocates that immune cell PD-L1 expression may predict a better clinical outcome. Overall, PD-L1(+) in immune cells were a favorable prognostic indicator. This may be because immune cell PD-L1 is regulated via an adaptive mechanism within the context of persistent tumor antigen-specific immune stimulation and reflects a pre-existing robust antitumor immunity, which may contribute to tumor surveillance and cytotoxic antitumor activity [32]. Similar to our results, previous studies have shown that PD-L1(+) in immune cells are associated with a favorable prognosis in gastric carcinomas [33-35]. In mouse models, PD-L1-expressing cytotoxic $\mathrm{T}$ cells seem to participate in antitumor immune responses via enhanced survival and potent expansion of cytotoxic $\mathrm{T}$ cells [36]. In contrast, PD-L1 in stromal immune cells has been shown to be involved in mediating the immune suppression of antitumor $\mathrm{T}$ cell responses [37]. Further studies are warranted to explain these contradictory data.

The present report suggests that FOXP3 ${ }^{+}$TILs may lean towards a good prognostic outcome. A possible explanation for our results is that $\mathrm{FOXP}^{+}$cells can suppress tumorpromoting proinflammatory cytokines that lead to malignancy [38]. This hypothesis is supported by our observation that a high population of $\mathrm{FOXP3}^{+}$cells was prevalent in early-stage tumors, as reported in previous studies [39]. Currently, the prognostic role of FOXP3 ${ }^{+}$TILs in gastric carcinomas remains unanswered; a high population of $\mathrm{FOXP}^{+}$TILs has been associated with both a better [22, 40] and worse prognosis [41], or not a reliable marker [6]. There is an argument that FOXP3 ${ }^{+}$TILs may have heterogeneous properties that are affected by the tumor site, and possibly the molecular subtype, mirroring different contexts within different tumor microenvironments $[42,43]$. 
Table 3 Comparison of PD-L1 Expression and Tumor-Infiltrating Lymphocytes in Each Molecular Group

\begin{tabular}{|c|c|c|c|}
\hline & Conventional $(n=429)$ & EBV-positive $(n=32)$ & MSI-high $(n=53)$ \\
\hline PD-L1 in tumor cells & & *a $P<0.001$ & $* \mathrm{~b} p<0.001$ \\
\hline Positive & 59 (14\%) & $15(47 \%)$ & $27(51 \%)$ \\
\hline Negative & $370(86 \%)$ & $17(53 \%)$ & $26(49 \%)$ \\
\hline PD-L1 in immune cells & & $* a \quad P<0.001$ & \\
\hline Positive & $186(43 \%)$ & $30(94 \%)$ & $28(53 \%)$ \\
\hline Absent & $243(57 \%)$ & $2(6 \%)$ & $25(47 \%)$ \\
\hline $\mathrm{CD}^{+}$ & & $*^{a} P<0.001$ & $*^{\mathrm{b}} P<0.001$ \\
\hline High & 189 (44\%) & $30(94 \%)$ & $38(72 \%)$ \\
\hline Low & $240(56 \%)$ & $2(6 \%)$ & $15(28 \%)$ \\
\hline $\mathrm{FOXP3}^{+}$ & & $*^{a} P=0.036$ & \\
\hline High & $199(46 \%)$ & $21(66 \%)$ & $20(38 \%)$ \\
\hline Low & $230(54 \%)$ & $11(34 \%)$ & $33(62 \%)$ \\
\hline PD-1 ${ }^{+}$ & & *a $P<0.001$ & \\
\hline High & $142(33 \%)$ & $23(72 \%)$ & $16(30 \%)$ \\
\hline Low & $287(67 \%)$ & $9(28 \%)$ & 37 (70\%) \\
\hline
\end{tabular}

EBV Epstein-Barr virus, MSI Microsatellite instability; Conventional, EBV-negative and non-MSI-high

$P$ values with statistically significant differences $(<0.05)$ are marked with an asterisk (*)

${ }^{\mathrm{a}} P$ value between EBV-positive gastric carcinomas and conventional gastric carcinomas

${ }^{\mathrm{b}} P$ value between MSI-high gastric carcinomas and conventional gastric carcinomas

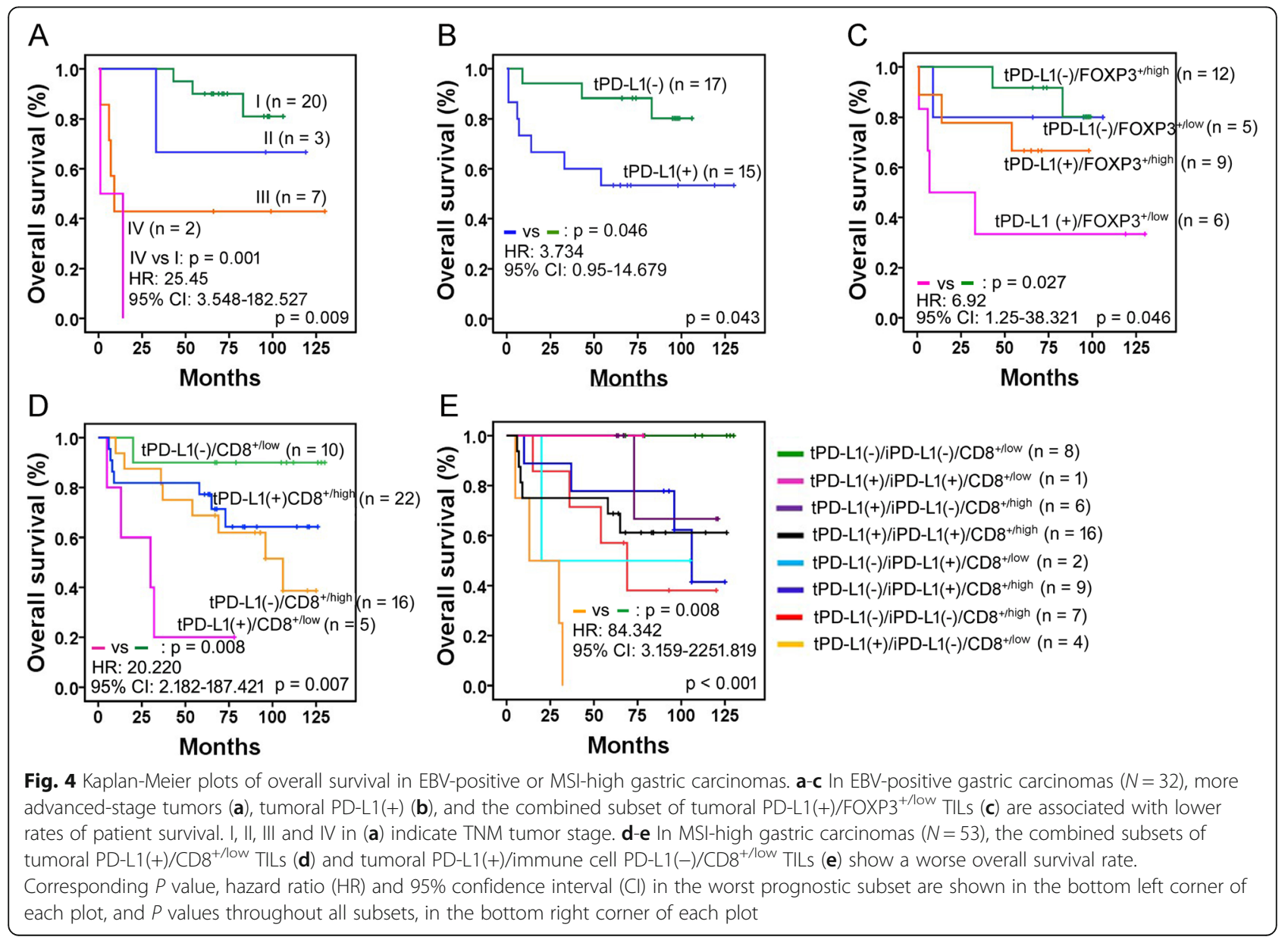


A

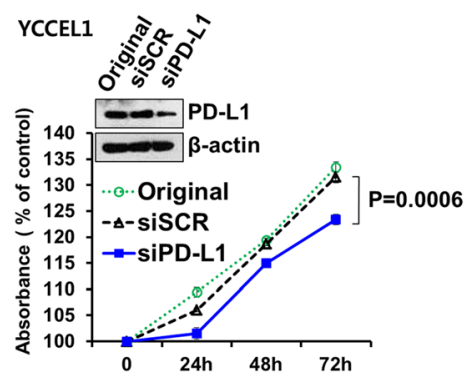

B

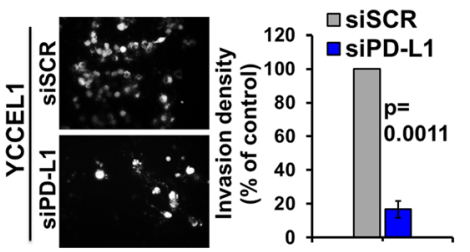

C

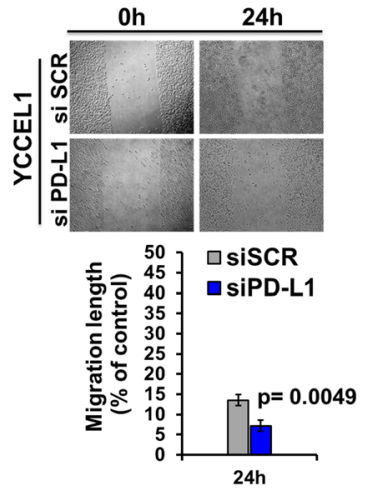

E
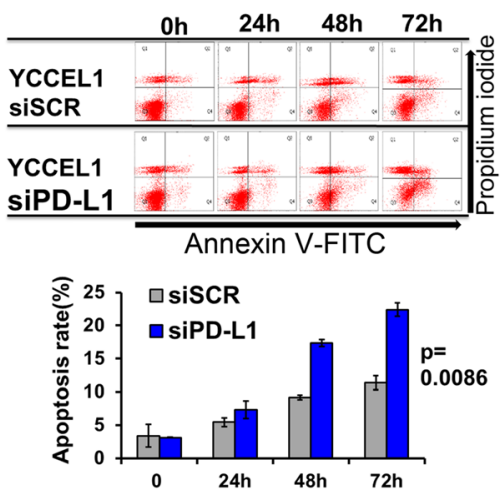
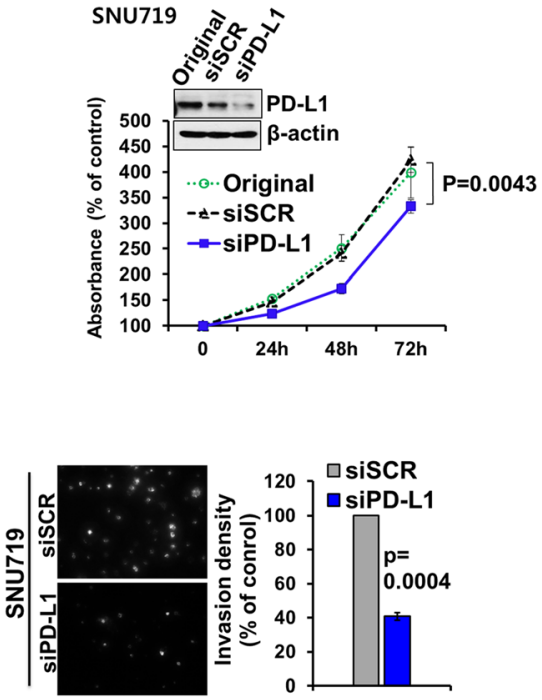

D
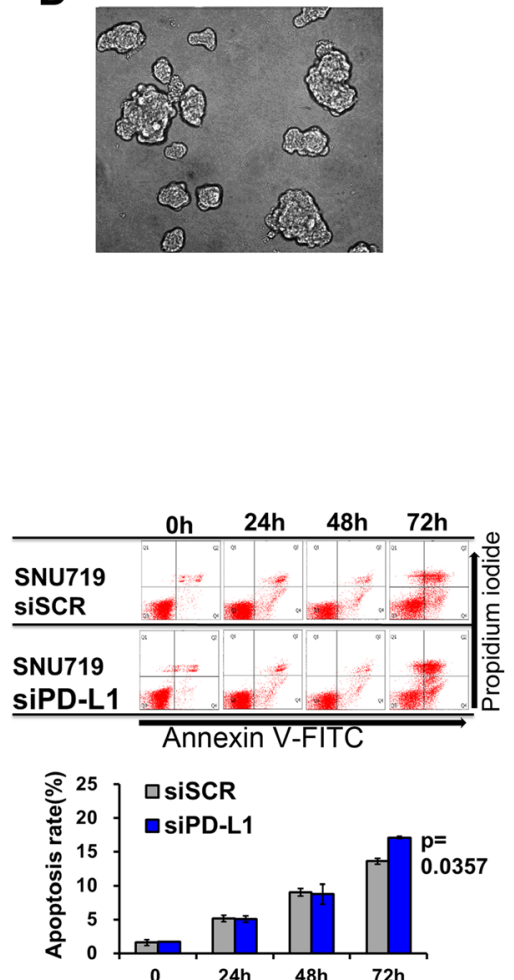

Fig. 5 Effect of PD-L1 knockdown on cell biologic properties in EBV-positive gastric carcinoma cell lines. In YCCEL1 (left column) and SNU719 cells (right column), cell proliferation (a), invasion (b) and migration (c) are lower in PD-L1-specific siRNA transfected cells than scrambled siRNAtransfected cells, and apoptosis $(\mathbf{e})$ is higher $(P<0.05)$. $\mathbf{d}$ There was a limitation on a wound-healing assay for migration in SNU719 cells; they grew in an aggregate pattern and thus, were not scratched with a pipette. X-axis denotes

In the present study, we propose that the extrinsic mechanism in tumoral PD-L1 expression may act more often in EBV-positive and MSI-high gastric carcinomas, indicating that PD-1/PD-L1 blockade immunotherapy may be advantageous in these patients. In our study, tumoral PD-L1(+)/ $\mathrm{CD}^{+/ \text {high }}$ TILs were more prevalent in 


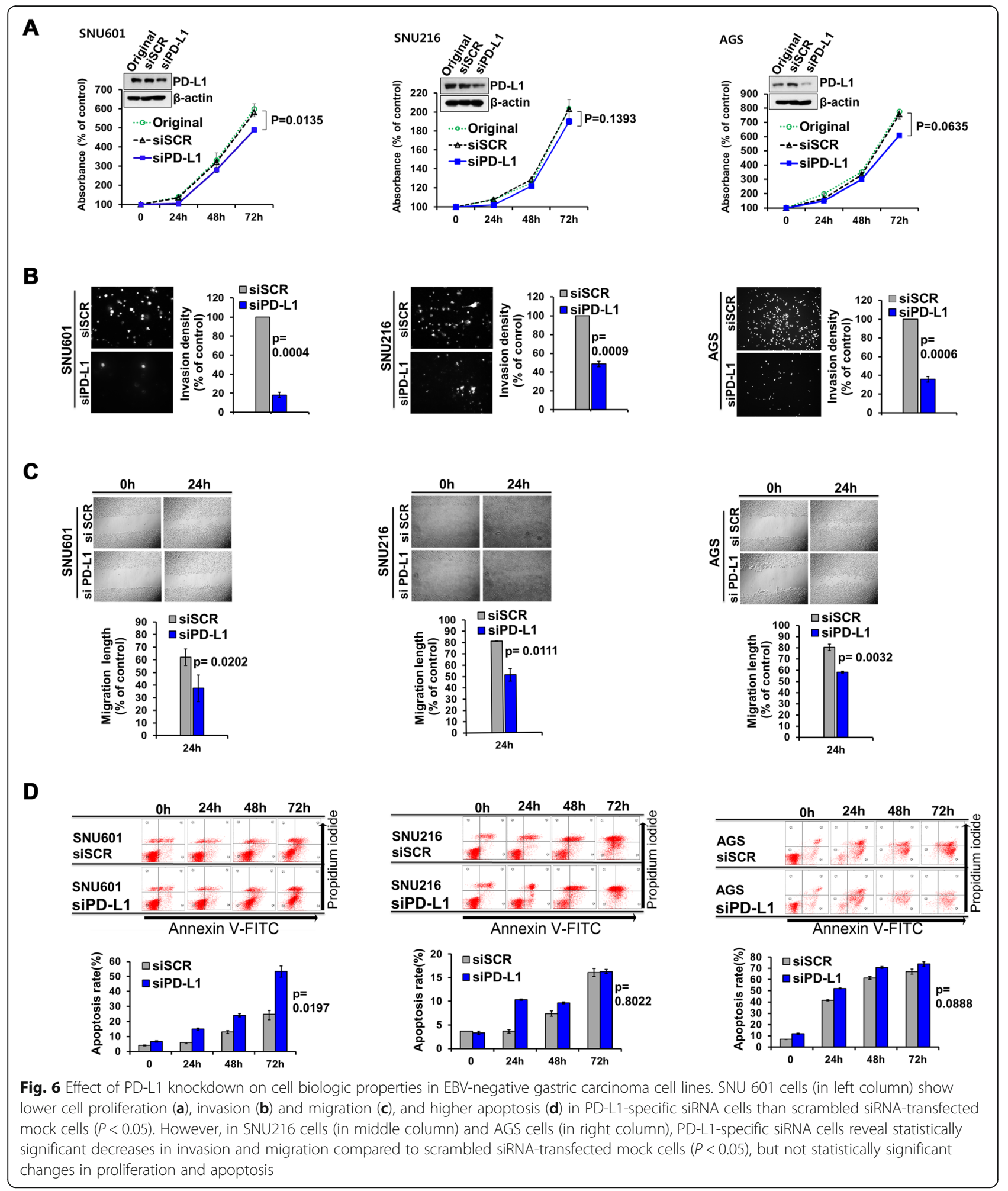

the EBV-positive and MSI-high groups than in the conventional group. This suggests that PD-L1 expression in tumor cells develops via an extrinsic mechanism (i.e., adaptive immune resistance), in which tumoral PD-L1 expression is extrinsically derived in response to the expression of inflammatory cytokines (in particular, to interferon- $\gamma$ that is released by $\mathrm{CD} 8^{+}$cytotoxic $\mathrm{T}$ cells) [44]. Furthermore, we found that diffuse expression of 
PD-L1 in a strong intensity was more frequently observed in the EBV-positive subgroup than in the conventional subgroup (13\% versus $5 \%$ of tumoral PD-L1 expressing-cases, respectively). Thus, extrinsic and intrinsic mechanisms in tumoral PD-L1 expression may work together more commonly in EBV-positive gastric carcinomas. The amplification of chromosomal region 9p24.1, which includes the PD-L1 gene, to promote intrinsic expression of PD-L1 has been reported in 15\% of EBV-positive gastric carcinomas [45]. Our results in the EBV-positive and MSI-high groups are consistent with those of previous reports: namely, the proportion of EBV-positive and MSI-high cases within the entire cohort, the more frequent tumoral PD-L1(+) and abundant $\mathrm{CD}^{+}$TILs in both subgroups, tumoral PD-L1(+) as an unfavorable prognostic indicator in the EBV-positive subgroup, and the mutually exclusive nature of EBVpositive and MSI-high status [12, 46, 47].

Our study has inherent limitations. First, our retrospective study merely represents immune context at the time of surgical resection, but not time-dependent dynamic immune heterogeneity. Second, we used only MLH1/MSH2 immunohistochemistry to screen cases for MSI multiplex PCR. We might miss out MSI cases with the isolated loss of PMS2 or MSH6, although those may be exceptional, at the least, in gastric carcinomas. Recently, Mathiak et al. reported that none of MSI-high gastric carcinomas has shown the isolated loss of MSH6 or PMS2 [48], which are more likely to be associated with Lynch syndrome due to a germline mutation in one of these genes [49]. Lastly, considering expression heterogeneity within the tumor, immunohistochemistry in as large a portion of tissue as possible, such as multiple full-sectioned tissues, would be better, but this is almost impractical. Instead, we utilized tissue microarray blocks composed of two tissue cores for each case in the deepest tumor invasion portion.

\section{Conclusions}

The prognostic impact of PD-L1 is determined by the tumor microenvironment, and statuses of EBV and MSI. Tumoral or immune cell PD-L1 on their own are not independent prognostic factors, but they have a prognostic significance in certain molecular groups. Notably, the combination of PD-L1 expression and CD8 ${ }^{+}$TILs may serve as an independent prognostic factor. The combined subset of "tumoral PD-L1(+)/immune cell PD-L1()/CD8 ${ }^{+/ \text {low }}$ TILs" shows a worse prognosis. This may be advantageous for combinatorial therapies of PD-L1/PD1 and cytotoxic T-lymphocyte associated antigen 4 blockades that would bring the activation and proliferation of effector $\mathrm{T}$ cells, thereby restoring the immune system toward attacking the tumor [50].

\section{Supplementary information}

Supplementary information accompanies this paper at https://doi.org/10. 1186/s13000-020-00979-z.

Additional file 1: Supplemental Figure 1. Correlation between PD-L1 expression and multiple lines of tumor-infiltrating lymphocytes (TILs). The tumoral PD-L1(+) subgroup (A-C) or immune cell PD-L1(+) subgroup (DF) displays many more $\mathrm{CD}^{+}, \mathrm{FOXP3}^{+}$, and $\mathrm{PD}-1^{+}$TILs than each respective PD-L1(-) subgroup.

Additional file 2: Supplemental Figure 2. Kaplan-Meier plots of overall survival in advanced gastric carcinomas (AGC) $(n=253)$. Among advanced gastric carcinomas, subgroup containing tumors with $C D 8^{+/ h i g h}$ (A), and MSI-high subgroup (B) show more favorable outcomes than $\mathrm{CD} 8^{+/ \text {low }}$ or conventional subgroup, respectively. Corresponding $P$ value, hazard ratio (HR) and 95\% confidence interval $(\mathrm{Cl})$ in the worst prognostic subset are shown in the bottom left corner of each plot, and $P$ values throughout all subsets, in the bottom right corner of each plot.

Additional file 3: Supplemental Figure 3. Comparison of the quantities of $\mathrm{CD}^{+}, \mathrm{FOXP3}^{+}$, and $\mathrm{PD}-1^{+}$TILs in the different molecular groups. $\mathrm{CD}^{+}(\mathrm{A}), \mathrm{FOXP3}^{+}(\mathrm{B})$, and PD-1 ${ }^{+}(\mathrm{C})$ TILs are more highly abundant in EBV-positive (EBV+) carcinomas than in conventional carcinomas. In MSI-high (MSI-H) carcinomas, only $\mathrm{CD}^{+}{ }^{+} \mathrm{TILS}$ are significantly enriched compared to conventional carcinomas. ${ }^{*} P<0.05$, ${ }^{*} P<0.01,{ }^{* *} P<$ 0.001

Additional file 4: Supplemental Figure 4. Distribution of tumoral PD$\mathrm{L} 1$ combined with $\mathrm{CD}^{+}$population in each molecular subgroup. The EBV-positive and MSI-high (MSI-H) subgroups show a higher frequency of tumoral PD-L1(+)/CD8 ${ }^{+/ \text {high }}$ TILs than the conventional subgroup $(P<$ 0.05, each).

Additional file 5: Supplemental Figure 5. Kaplan-Meir plots of overall survival in each tumor stage according to the density of CD8 ${ }^{+}$TILs. Corresponding $P$ value, hazard ratio $(\mathrm{HR})$ and $95 \%$ confidence interval $(\mathrm{Cl})$ in the worst prognostic subset are shown in the bottom left corner of each plot, and $P$ values throughout all subsets, in the bottom right corner of each plot.

Additional file 6: Supplemental Table 1. Correlation Between PD-L1 Expression and Tumor-Infiltrating Lymphocytes (TILs) in the Entire Cohort $(N=514)$

Additional file 7: Supplemental Table 2. Univariate and Multivariate Analyses in the Entire Cohort ( $N=514$ ) (corresponding to Fig. 2a, b \& e)

Additional file 8: Supplemental Table 3. Univariate and Multivariate Analyses in EBV-positive Gastric Carcinomas $(n=32)$ (corresponding to Fig. 4a \& c)

Additional file 9: Supplemental Table 4. Univariate Analysis in MSIhigh Gastric Carcinomas ( $n=53$ ) (corresponding to Fig. $4 d$ \& e)

Additional file 10: Supplemental Table 5. Comparison of

Clinicopathologic Characteristics, and Statuses of PD-L1, FOXP3 ${ }^{+}$, and PD$1^{+}$According to the Density of $\mathrm{CD}^{+}$TILs in the Entire Cohort $(N=514)$

\section{Abbreviations}

AGC: Advanced gastric carcinoma; CTLA4: Cytotoxic T-lymphocyte associated antigen 4; EBV: Epstein-Barr virus; FOXP3: Forkhead box P3; MSI: Microsatellite instability; PD-1: Programmed death-1; PD-L1: Programmed death-ligand 1; pTNM: pathological tumor-node-metastasis; TIL: Tumor infiltrating lymphocyte

\section{Acknowledgements}

This work was supported by the Basic Science Research Program of the National Research Foundation of Korea, which is funded by the Ministry of Education, Republic of Korea (2016R1D1A1B01010316). The authors thank Hee Song, M.S. and Chan Jin Yoon, M.S. for cell-based assays.

\section{Authors' contributions}

EC was responsible for evaluation of pathological features, the statistical analysis and manuscript writing. MSC conceived, designed and coordinated the study, reviewed pathological features, statistical data and results of cellbased assays, provided financial support, and wrote the manuscript. SB 
participated in construction of tissue microarray blocks, and the statistical analysis. HJ performed the statistical analysis and confirmation. KCJ and HK reviewed immunohistochemical interpretation and statistical data. KLL, WK JHP, KHK, JSK and ISC were responsible for collection of clinical outcome data and statistical interpretation, and involved in study design. DSH, HSA and SCH were responsible for collection of surgical cases. All authors read and approved the final manuscript.

\section{Funding}

This work was supported by the Basic Science Research Program of the National Research Foundation of Korea, which is funded by the Ministry of Education (2016R1D1A1B01010316).

\section{Availability of data and materials}

Please contact the corresponding author for data requests.

\section{Ethics approval and consent to participate}

\section{All human tissue specimens were obtained during diagnostic and} therapeutic surgery. This retrospective study was performed using the tissueparaffin block samples stored after pathologic diagnosis, and all of the samples were anonymized beforehand. This retrospective study was approved by the Institutional Review Board of Seoul National University Boramae Medical Center under the condition of anonymization (IRB No. 20150907/162015-124/101). The study was conducted in accordance with the principles of the Declaration of Helsinki.

\section{Consent for publication}

Not applicable.

\section{Competing interests}

The authors declare no conflicts of interest.

\section{Author details}

${ }^{1}$ Department of Pathology, Seoul National University Boramae Hospital, Seoul National University College of Medicine, 20 Boramae-ro 5-gil, Dongjak-gu, Seoul 07061, Republic of Korea. ${ }^{2}$ Medical Research Collaborating Center Department of Biostatistics, Seoul National University Boramae Hospital, Seoul, Republic of Korea. ${ }^{3}$ Department of Pathology, Seoul National University Hospital, Seoul National University College of Medicine, Seoul, Republic of Korea. ${ }^{4}$ Department of Internal Medicine, Seoul National University Boramae Hospital, Seoul National University College of Medicine, Seoul, Republic of Korea. ${ }^{5}$ Department of Surgery, Seoul National University Boramae Hospital, Seoul National University College of Medicine, Seoul, Republic of Korea.

Received: 1 January 2020 Accepted: 19 May 2020 Published online: 04 June 2020

\section{References}

1. Ferlay J, Colombet M, Soerjomataram I, et al. Estimating the global cancer incidence and mortality in 2018: GLOBOCAN sources and methods. Int J Cancer. 2019:144:1941-53.

2. Muro K, Chung HC, Shankaran V, et al. Pembrolizumab for patients with PDL1-positive advanced gastric cancer (KEYNOTE-012): a multicentre, openlabel, phase 1b trial. Lancet Oncol. 2016;17:717-26.

3. Taube JM, Galon J, Sholl LM, et al. Implications of the tumor immune microenvironment for staging and therapeutics. Mod Pathol. 2018;31:214-34.

4. Sunshine J, Taube JM. PD-1/PD-L1 inhibitors. Curr Opin Pharmacol. 2015; 23:32-8.

5. Sanmamed MF, Chen L. Inducible expression of B7-H1 (PD-L1) and its selective role in tumor site immune modulation. Cancer J. 2014;20:256261.

6. Ying L, Yan F, Meng Q, et al. PD-L1 expression is a prognostic factor in subgroups of gastric cancer patients stratified according to their levels of CD8 and FOXP3 immune markers. Oncoimmunology. 2018;7:e1433520.

7. Restifo NP, Dudley ME, Rosenberg SA. Adoptive immunotherapy for cancer: harnessing the T cell response. Nat Rev Immunol. 2012;12:269-81.

8. Wherry EJ. T cell exhaustion. Nat Immunol. 2011;12:492-9.

9. Francisco LM, Salinas VH, Brown KE, et al. PD-L1 regulates the development, maintenance, and function of induced regulatory T cells. J Exp Med. 2009: 206:3015-29.
10. Tumeh PC, Harview CL, Yearley JH, et al. PD-1 blockade induces responses by inhibiting adaptive immune resistance. Nature. 2014;515:568-71.

11. Vrána $D$, Matzenauer $M$, Neoral Č, et al. From tumor immunology to immunotherapy in gastric and esophageal cancer. Int J Mol Sci. 2018;20. https://doi.org/10.3390/ijms20010013.

12. Zhang $L$, Qiu $M$, Jin $Y$, et al. Programmed cell death ligand 1 (PD-L1) expression on gastric cancer and its relationship with clinicopathologic factors. Int J Clin Exp Pathol. 2015;8:11084-91.

13. Chang $H$, Jung WY, Kang $Y$, et al. Programmed death-ligand 1 expression in gastric adenocarcinoma is a poor prognostic factor in a high CD8+ tumor infiltrating lymphocytes group. Oncotarget. 2016;7:80426-34.

14. Eto S, Yoshikawa K, Nishi M, et al. Programmed cell death protein 1 expression is an independent prognostic factor in gastric cancer after curative resection. Gastric Cancer. 2016;19:466-71.

15. Thompson ED, Zahurak M, Murphy A, et al. Patterns of PD-L1 expression and CD8 T cell infiltration in gastric adenocarcinomas and associated immune stroma. Gut. 2017:66:794-801.

16. Kim JW, Nam KH, Ahn SH, et al. Prognostic implications of immunosuppressive protein expression in tumors as well as immune cell infiltration within the tumor microenvironment in gastric cancer. Gastric Cancer. 2016:19:42-52.

17. Kawazoe A, Kuwata T, Kuboki Y, et al. Clinicopathological features of programmed death ligand 1 expression with tumor-infiltrating lymphocytes, mismatch repair, and Epstein-Barr virus status in a large cohort of gastric cancer patients. Gastric Cancer. 2017;20:407-15.

18. Lauren P. The two histological main types of gastric carcinoma: diffuse and so called intestinal-type carcinoma. An attempt at a histo-clinical classification. Acta Pathol Microbiol Scand. 1965:64:31-49.

19. Edge SB, Byrd DR, Compton CC, et al. AJCC cancer staging manual. 7th ed. New York: Springer-Verlag; 2009. p. 117-26.

20. Schats KA, Van Vré EA, Boeckx C, et al. Optimal evaluation of programmed death ligand-1 on tumor cells versus immune cells requires different detection methods. Arch Pathol Lab Med. 2018;142:982-91.

21. Ma C, Patel $K$, Singhi AD, et al. Programmed death-ligand 1 expression is common in gastric cancer associated with Epstein-Barr virus or microsatellite instability. Am J Surg Pathol. 2016:40:1496-506.

22. Wang J, Reiss KA, Khatri R, Jaffee E, Laheru D. Immune therapy in G malignancies: a review. J Clin Oncol. 2015;33:1745-53.

23. Kang BW, Seo AN, Yoon S, et al. Prognostic value of tumor-infiltrating lymphocytes in Epstein-Barr virus-associated gastric cancer. Ann Oncol. 2016;27:494-501.

24. Bae YS, Kim H, Noh SH, Kim H. Usefulness of immunohistochemistry for microsatellite instability screening in gastric cancer. Gut Liver. 2015:9:629-35.

25. Boland CR, Thibodeau SN, Hamilton SR, et al. A national cancer institute workshop on microsatellite instability for cancer detection and familial predisposition: development of international criteria for the determination of microsatellite instability in colorectal cancer. Cancer Res. 1998;58:5248-57.

26. Jeong JY, Woo JH, Kim YS, et al. Nuclear factor-kappa B inhibition reduces markedly cell proliferation in Epstein-Barr virus-infected stomach cancer, but affects variably in Epstein-Barr virus-negative stomach cancer. Cancer Investig. 2010;28:113-9.

27. Kim DH, Chang MS, Yoon CJ, et al. Epstein-Barr virus BARF1-induced NFkB/ miR-146a/SMAD4 alterations in stomach cancer cells. Oncotarget. 2016;7: 82213-27.

28. Li J, Chen L, Xiong Y, et al. Knockdown of PD-L1 in human gastric cancer cells inhibits tumor progression and improves the cytotoxic sensitivity to CIK therapy. Cell Physiol Biochem. 2017:41:907-20.

29. Shi SJ, Wang LJ, Wang GD, et al. B7-H1 expression is associated with poor prognosis in colorectal carcinoma and regulates the proliferation and invasion of HCT116 colorectal cancer cells. PLoS One. 2013;8:e76012

30. Chen J, Jiang CC, Jin L, et al. Regulation of PD-L1: a novel role of prosurvival signalling in cancer. Ann Oncol. 2016;27:409-16.

31. Yu J, Wang $X$, Teng $F$, et al. PD-L1 expression in human cancers and its association with clinical outcomes. Onco Targets Ther. 2016;9:5023-39.

32. Giannakis M, Mu XJ, Shukla SA, et al. Genomic correlates of immune-cell infiltrates in colorectal carcinoma. Cell Rep. 2016;17:1206.

33. Kim HR, Ha SJ, Hong MH, et al. PD-L1 expression on immune cells, but not on tumor cells, is a favorable prognostic factor for head and neck cancer patients. Sci Rep. 2016:6:36956.

34. Cho J, Lee J, Bang $H$, et al. Programmed cell death-ligand 1 expression predicts survival in patients with gastric carcinoma with microsatellite instability. Oncotarget. 2017;8:13320-8. 
35. Choi Y, Kim H, Shin SJ, et al. Microsatellite Instability and Programmed Cell Death-Ligand 1 Expression in Stage II/III Gastric Cancer: Post Hoc Analysis of the CLASSIC Randomized Controlled Study. Ann Surg. 2019;270:309-16.

36. Pulko V, Harris K, Liu X, et al. B7-H1 expressed by activated CD8 T cells is essential for their survival. J Immunol. 2011;187:5606-14.

37. Lau J, Cheung J, Navarro A, et al. Tumour and host cell PD-L1 is required to mediate suppression of anti-tumour immunity in mice. Nat Commun. 2017; 8:14572.

38. Balkwill F, Coussens LM. Cancer: an inflammatory link. Nature. 2004;431:405-6.

39. Kim KJ, Lee KS, Cho HJ, et al. Prognostic implications of tumor-infiltrating FoxP3+ regulatory T cells and CD8+ cytotoxic T cells in microsatelliteunstable gastric cancers. Hum Pathol. 2014;45:285-93.

40. Haas M, Dimmler A, Hohenberger W, et al. Stromal regulatory T-cells are associated with a favourable prognosis in gastric cancer of the cardia. BMC Gastroenterol. 2009:9:65.

41. Perrone G, Ruffini PA, Catalano V, et al. Intratumoural FOXP3-positive regulatory $T$ cells are associated with adverse prognosis in radically resected gastric cancer. Eur J Cancer. 2008;44:1875-82.

42. deLeeuw RJ, Kost SE, Kakal JA, et al. The prognostic value of FoxP3+ tumorinfiltrating lymphocytes in cancer: a critical review of the literature. Clin Cancer Res. 2012;18:3022-9.

43. Ladoire S, Martin F, Ghiringhelli F. Prognostic role of FOXP3+ regulatory T cells infiltrating human carcinomas: the paradox of colorectal cancer. Cancer Immunol Immunother. 2011;60:909-18.

44. Zou W, Chen L. Inhibitory B7-family molecules in the tumour microenvironment. Nat Rev Immunol. 2008:8:467-77.

45. Cancer Genome Atlas Research Network. Comprehensive molecular characterization of gastric adenocarcinoma. Nature. 2014;513:202-9.

46. Chang MS, Lee HS, Kim HS, et al. Epstein-Barr virus and microsatellite instability in gastric carcinogenesis. J Pathol. 2003;199:447-52.

47. Kim ST, Cristescu R, Bass AJ, et al. Comprehensive molecular characterization of clinical responses to PD-1 inhibition in metastatic gastric cancer. Nat Med. 2018:24:1449-58.

48. Mathiak M, Warneke VS, Behrens H-M, et al. Clinicopathologic characteristics of microsatellite instable gastric carcinomas revisited: urgent need for standardization. Appl Immunohistochem Mol Morphol. 2017;25:12-24.

49. Samowitz WA. Evaluation of colorectal cancers for lynch syndrome: practical molecular diagnostics for surgical pathologists. Mod Pathol. 2015;28:S109-13.

50. Ribas A, Hu-Lieskovan S. What does PD-L1 positive or negative mean? J Exp Med. 2016;213:2835-0.

\section{Publisher's Note}

Springer Nature remains neutral with regard to jurisdictional claims in published maps and institutional affiliations.

Ready to submit your research? Choose BMC and benefit from:

- fast, convenient online submission

- thorough peer review by experienced researchers in your field

- rapid publication on acceptance

- support for research data, including large and complex data types

- gold Open Access which fosters wider collaboration and increased citations

- maximum visibility for your research: over $100 \mathrm{M}$ website views per year

At $\mathrm{BMC}$, research is always in progress.

Learn more biomedcentral.com/submissions 